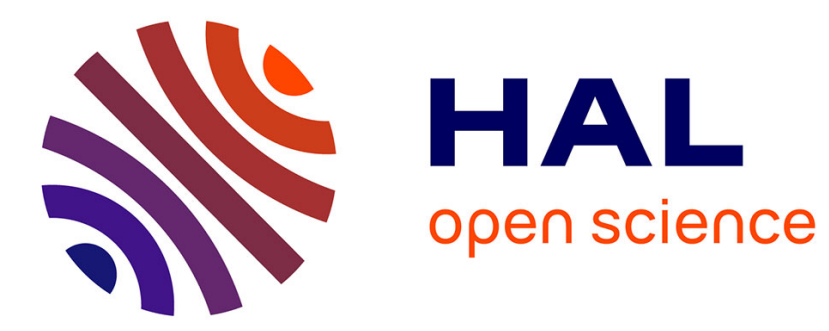

\title{
Orienting product performance improvement: application to mechatronics
}

Pierre Couturier, Abdelhak Imoussaten, Jacky Montmain

\section{To cite this version:}

Pierre Couturier, Abdelhak Imoussaten, Jacky Montmain. Orienting product performance improvement: application to mechatronics. 20th International Conference on Research and Education in Mechatronics (REM), May 2019, Wels, Austria. 10.1109/REM.2019.8744137 . hal-02098628

\section{HAL Id: hal-02098628 \\ https://hal.science/hal-02098628}

Submitted on 18 Feb 2020

HAL is a multi-disciplinary open access archive for the deposit and dissemination of scientific research documents, whether they are published or not. The documents may come from teaching and research institutions in France or abroad, or from public or private research centers.
L'archive ouverte pluridisciplinaire HAL, est destinée au dépôt et à la diffusion de documents scientifiques de niveau recherche, publiés ou non, émanant des établissements d'enseignement et de recherche français ou étrangers, des laboratoires publics ou privés. 


\title{
Orienting product performance improvement: application to mechatronics
}

\author{
Pierre Couturier, Abdelhak Imoussaten, Jacky Montmain \\ LGI2P, IMT Mines Ales, Univ Montpellier, Ales, France \\ Firstname.Name@mines-ales.fr
}

\begin{abstract}
On which criteria design efforts have to be focused on when pursuing the improvement of a product so as to provide most satisfaction to customers? The answer cannot be so obvious at the earliest steps of the design process when available knowledge is still incomplete and vague. Moreover, the problem becomes more complicated when the decision maker has to express some sophisticated preferences on the set of solutions. In this paper we propose to contribute to this issue by proposing an original qualitative computation of the worth- index, the purpose of which is to estimate the mean expected gain in performance improvement on a set of interrelated criteria. An illustration is given in the mechatronics field.
\end{abstract}

Keywords-qualitative evaluation; product improvement; multi criteria decision support; mechatronic design;

\section{INTRODUCTION}

The question addressed in this paper is: how to identify among the appraisal criteria of a product the ones on which it is the most likely profitable to concentrate improvement efforts when design decision consequences are still imprecisely known and when assessment of products is multidimensional? This problem is posed to manufacturers who must, in a highly competitive and unstable environment, constantly improve their products to remain competitive and satisfy their customers while minimizing incurred costs and risk taking. Such an issue is particularly critical in Mechatronics due to the multidisciplinary dimensions of mechatronic products, the coupling phenomena between components and the coarse predictive modelling possibilities available during the preliminary design stage [1][2].

Indeed, at this stage, engineers cannot precisely estimate the impacts of design decisions; generally, they can only estimate them in a purely qualitative manner. Defining achievable targets is thus a risky and not deterministic process. That is why decisional strategies have to be set out to define, compare and select potential improvement actions with respect to stakeholder's needs. The relationships existing between the multiple performance criteria of the product significantly complicate the choice. Hence, sophisticated mathematical models are required to deal with multiple assessment criteria in such an uncertain environment [3][4].

It is the purpose of multi-criteria decision analysis (MCDA), to compare solutions according to the stakeholders' preferences. An aggregation operator may be identified to assess all alternatives w.r.t the criteria and the customer's preferences.
Aggregation operators are often limited to simple linear operators such as the weighted arithmetic mean. However, such an aggregation operator requires independence between criteria, which is a rather drastic hypothesis [5]. Indeed, in practice, preferential interactions may make counter-intuitive the overall result of elementary performance improvements according to specific criteria. The family of fuzzy integrals like the Choquet integral and the Sugeno integral allows modelling the preferential dependencies between performances in the decisional strategy through fuzzy measures [6].

Recently, some works in MCDA exploit the preferences model, in particular those using Choquet integral, to estimate the expected gain when improving a product/system on a set of criteria [7] [8] [9]. The authors associate to any coalition of criteria an index named worth index that measures for any considered state of the product/system, the mean expected gain of all the possible improvements. In their initial forms, these models assume that all the improvements are uniformly probable whatever their magnitude. In this paper we propose a qualitative approach of the worth index based on the Sugeno integral in order to identify the most pertinent criteria on which a product should be improved.

Section II describes the addressed problem in mechatronics. Section III presents some necessary definitions of some wellknown qualitative multiple criteria aggregation operators in MCDA field but not so spread in the Mechatronics' one. Section IV introduces our proposal which is illustrated in Section V through an example in the mechatronic field. Some related works are cited in Section VI before concluding.

\section{PROBLEM RELEVANCE IN MECHATRONICS}

Mechatronics design is an interdisciplinary activity which aims at developing, at lowest costs, high quality products by integrating always more functionality while respecting severe geometrical constraints. Architectural decisions made at the earliest of the design stages influence most of the mechatronic product development costs [2]. However, rating the merit factors of preliminary design choices needs to take into consideration many constraints and interactions but is hindered by imprecision and uncertainty. Hence, the problem of assessing the consequences on the final product performance of early design choices is quite a critical issue in mechatronics [10].

In order to design complex systems, Systems Engineering (SE) [11][12] is an interdisciplinary and collaborative approach the interest of which, particularly for multidisciplinary fields such 
as mechatronics, is to purvey the design team members with common and sharable concepts and vocabulary relative to the system level, i.e. a level above the particular discipline pillars[10]. It is only when the system level concepts and architectures have been properly defined that the many disciplinary components can be specified, developed in parallel and then integrated in a final product as described by the V-model of the VDI2206 guideline [13]. However, SE does not promote any evaluation approach or method to choose among different design alternatives nor to orientate the design efforts.

Some design methods such as Axiomatic Design guide the engineers to produce well designed systems while respecting both the independence axiom and the information axiom [14]. Among the evaluation methods, the Pugh matrix [15] is a type of matrix diagram that allows for the comparison of several conceptual design alternatives: the columns of the Pugh matrix are labelled with design concepts and the rows are labelled with criteria. All the concepts are evaluated on each criterion relatively to one concept chosen as a baseline. However, such methods do not help orientate design effort and do not answer to questions such as: which characteristics of a product are the most valuable to improve? Whereas QFD method does in some way. Quality Function Development (QFD) fosters an enhanced consideration of the customer's voice [16]. Four successive 'Houses of Quality' as the one shown in Figure 1 are based on matrix formalism and aim at covering part of the product life from the customer's needs definition until the production processes choices.

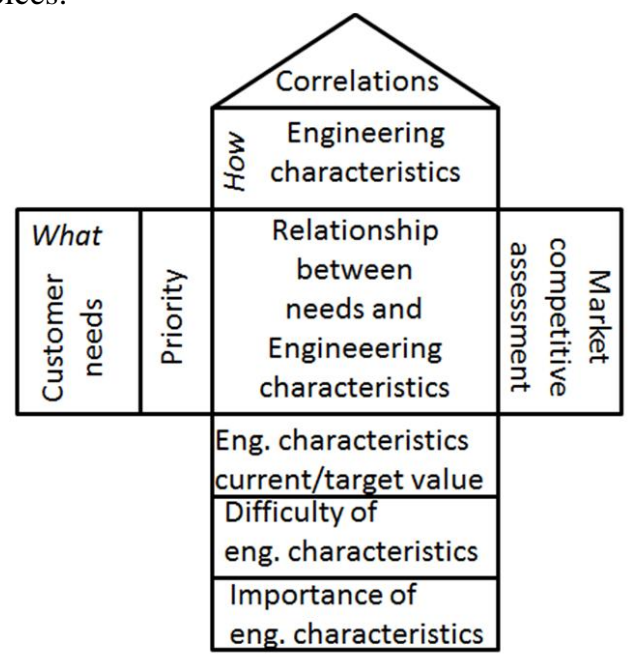

Fig. 1. QFD House of quality

QFD is a powerful framework which can gather important information to take into account so as to define the importance of engineering characteristics (the How) but QFD does not suggests any specific tool to exploit these data. Thus, many research works can be find in the literature to fill this gap and to overcome QFD limitations but few of them deal with the criteria interdependency issue [17][18]. Consequently, the aim of the method proposed in Section IV is to contribute to help the architects of complex products such as mechatronics ones to orientate the design effort taking into account the uncertainty context of preliminary design and the diversity of stakeholders' needs. But let us start by some reminders and definitions about qualitative multiple criteria aggregation operators.

\section{IMPROVEMENT IN A MULTI CRITERIA FRAMEWORK: REMINDERS AND NOTATIONS}

In this section we remind the cardinal version of the worth index and some characteristics and notations of the ordinal framework.

\section{A. The worth index in the cardinal setting}

Let us denote by $N=\{1,2, \ldots, n\}$ a set of attributes (characteristics of interest for the stakeholders) where the $i^{\text {th }}$ attribute takes its values in a set denoted $X_{i}$. For simplification purposes, we consider that the step of building the utility scales has already been done [6]. Thus, we consider that all the attributes take their values in the same scale, i.e., $X_{i}=[0,1], \forall i \in N$. Therefore, we consider that all conditions are met for the existence of additive aggregation operators, e.g., weighted sum, and non-additive ones e.g., the Choquet integral [19][20][21][22]. Let $H:[0,1]^{n} \rightarrow[0,1]$ be an aggregation operator. The evaluation of an alternative, e.g., a product or a system, is presented by its performance on the attributes of $N$. Then an alternative $x$ is denoted by the vector of its performance $\left(x_{1}, \ldots, x_{n}\right) \in$ $[0,1]^{n}$. Using the operator $H$, the global evaluation of $x$ is $H(x)$.

Definition 1: We consider that an alternative $y$ is an improvement of the alternative $x$ if: $H(y)>H(x)$ and $y_{i} \geq x_{i}, \forall i \in$ $N$. The definition 1 shows that the improvement from $x$ that we consider in this paper are those maintaining at least the performances obtained with $x$ and it exists at least an attribute $j$ where $y_{j}>x_{j}$.

\section{B. Worth index}

In [23], the author is interested to determine the subset of criteria on which an alternative should be first improved in order to raise its overall score to the greatest extent possible. He introduces the worth index denoted by $W_{H}(x, I)$, for the aggregation operator $H$ and the initial vector of performance $x$, that assesses the expected gain that the improvement of the coalition of criteria $I \subset N$ could bring to the overall improvement of $x$. The mathematical expression of the worth-index is as follows: $W_{H}(x, I)=\int_{0}^{1}\left[H\left((1-\lambda) x_{I}+\lambda 1_{I}, x_{-I}\right)-H(x)\right] d \lambda$

where for any $I \subseteq N, t=\left(y_{I}, z_{-I}\right)$ is the vector $\in[0,1]^{n}$ with $t_{i}=y_{i}$ for $i \in I$ and $t_{i}=z_{i}$ if $i \in N \backslash I$. The choice to integrate in formula (1) along the hyper bisector ensures a homogeneous improvement of all the criteria in I. The main drawback in this approach is that all performances are supposed to be equiprobable which is obviously not the case in practice (large improvements are supposed less probable than tiny ones).

In [24], the authors propose an extension of the worth index in a probabilistic framework where, a probability value is assigned to each improvement. The use of this approach depends on the availability of learning data which may be not the case in the preliminary design stages where experts are mostly able to provide qualitative estimations. 


\section{Ordinal Setting and Sugeno integral}

When the assessments collected on a system have a poor structure, e.g., ordinal information, it is common practice to make arbitrary assumptions in order to use the properties of the cardinal setting. To avoid these assumptions, it is preferable to use ordinal information as it is, by contenting itself with the poor structure it induces. In such a case, the above approaches based on the construction of utilities as part of the multiple criteria aggregation are no longer valid. Indeed, the construction of some aggregation operators, e.g., weighted mean and Choquet integral operators, are based on the difference measurement on the scale of attributes which it is no longer possible with ordinal data. For ordinal scales, only minimum, maximum operations and the combinations of these operations, e.g., median, are allowed. The Sugeno integral is a generalization of all classical operations on ordinal scales. Moreover, it is an appropriate operator to aggregate ordinal values related to interactive criteria [23]. Sugeno integrals are based on a capacity that allows taking into account the preferential interactions between criteria in the aggregated result.

Let $K$ be a finite ordinal scale with $1_{K}$ its highest value and $0_{K}$ its lowest value, e.g., $K=\left\{0_{K}=\right.$ null, bad, medium, good, $1_{K}=$ top $\}$.

Definition 2: A set function $\mu: 2^{N} \rightarrow K$ is called a fuzzy measure or also called capacity if it satisfies the following conditions:

1. $\mu(\varnothing)=0_{K}$ (the importance of the empty set is null);

2. $\mu(N)=1_{K}$ (the maximum importance is assigned to $N)$;

3. $\mu$ is monotonic non decreasing for inclusion, i.e., for any $A, B \subseteq N, A \subseteq B \Rightarrow \mu(A) \leq \mu(B)$.

The monotonicity of $\mu$ means that the importance of a subset of criteria cannot decrease when new criteria are added to it. In the context of MCDA, $\mu(A)$ represents the importance of a subset of criteria $A \subseteq N$.

Definition 3: Let $k=\left(k_{1}, k_{2}, \ldots, k_{n}\right) \in K^{n}$ a vector of values in $K$. The Sugeno integral of $k$ with respect to $\mu$, denoted $S_{\mu}(k)$ is given by:

$$
S_{\mu}(k)=\max _{\mathrm{i}=1, \mathrm{n}}\left(\min \left(k_{\sigma(i)}, \mu\left(A_{\sigma(i)}\right)\right)\right.
$$

where $\sigma$ is a permutation on $N$ such that $k_{\sigma(1)} \leq k_{\sigma(2)} \leq \cdots \leq$ $k_{\sigma(n)}$ and $A_{\sigma(i)}=\{\sigma(i), \ldots, \sigma(n)\}$.

For a simple representation, the Sugeno integral based on the capacity $\mu$ can also be written using the median operator [25]:

$$
S_{\mu}(k)=\operatorname{med}\left(k_{\sigma(1)}, \ldots, k_{\sigma(\mathrm{n})}, \mu\left(A_{\sigma(1)}\right), \ldots, \mu\left(A_{\sigma(n)}\right)\right)
$$

In the classical aggregation operation, the value of attributes are weighted by their importance in the global result of an alternative. In sophisticated operators like Sugeno or Choquet integrals, the rank of the attribute values and the importance of the subsets of attributes are the ingredients used to calculate the global result. The higher is the score of an alternative on the subsets of attributes considered as important by the decision maker, the higher is the global result of the alternative [25]. This integral is monotone, and presents a compromise behavior. It searches the importance exceeding a certain level, and then performs a compromise deal between the selected values.

\section{AN ORDINAL WORTH-INDEX}

In this section, we are interested in determining the criteria that should be improved first to satisfy as much as possible the stakeholders expectations when the ordinal scales are considered for attributes and Sugeno integral is used as the aggregation operator. For this purpose, we propose an extension of the worth index to the ordinal setting.

Let $k^{0}=\left(k_{1}^{0}, k_{2}^{0}, \ldots, k_{n}^{0}\right) \in K^{n}$ the starting point. By considering the subset of criteria $I \subseteq N$, several vectors of performances $k \in K^{n}$ are possible improvements on $I$ (see definition 1 ). We denote by $k^{1}$, the vector of performances improving $k^{0}$ and obtained by increasing each $k_{i}^{0}$ one step up (steps are the levels defined in the values ordinal scale $K$ ) for all the criteria in $I$. The same operation is done to obtain $k^{2}$ form $k^{1}$ and so on. Let us denote by $\operatorname{Improvt}_{k^{0}}(I)$ the set of all vectors obtained from $k^{0}$ by improving $k^{0}, k^{1}, \ldots$ In other words, similarly to (1), only improvements obtained by progressing from $k^{0}$ to $1_{I}$ along the diagonal of the $|\mathrm{I}|$-cube are considered (where $|\mathrm{I}|$ denotes the cardinal of $I$ ). In similar way as in (1) and by using the counter part of the sum operator in the ordinal setting, the expected gain obtained by improving $k^{0}$ on the subset of attributes is the median of the improvement performances of the set $\operatorname{Improvt}_{k^{0}}(I)$. The median which is an associative qualitative compensatory aggregation operator, provides how worth it is improving $k^{0}$ on the criteria of $I$. Thus the ordinal worth index using Sugeno integral is proposed as follows:

$$
W_{S_{\mu}}\left(k^{0}, I\right)=\operatorname{med}\left(S_{\mu}\left(k^{0}\right), S_{\mu}\left(k^{1}\right), \ldots S_{\mu}\left(k^{\max }\right)\right.
$$

where $k^{\max }=\left(1_{I}, k_{N \backslash I}^{0}\right)$.

This model assumes that all the improvements are uniformly probable regardless of their magnitude. Such an assumption may be questionable in practice. For instance, the maximum score values should be out of reach for some criterion because of resource or feasibility limitations. One simple way to take such saturation constraints into account is to define the maximum value $k_{i}^{\max }$ that the $i^{\text {th }}$ performance can't exceed. In such case $k^{\max }=\left(k_{I}^{\max }, k_{N \backslash I}^{0}\right)$.

\section{A MECHATRONIC APPLICATION}

\section{A. Presentation of the example}

The illustrative example is similar to the one presented in previous publications [26][27]. The aim is to build a small (a $0.3 \mathrm{~m}$ square cube) autonomous mobile robot able to compete with other robots. Each robot has to achieve the following mission as quickly as possible: to grasp and transport some loads between several stock devices spread over a plan playground. In the framework of this paper, we consider that several robots already exist (reuse of available prototypes). The objective is then to make a decision on which criteria the improvement of the existing robots should be concentrated in priority in order to win the challenge. It is clear that improving all criteria at the same time should be the best issue, but it would demand large 
efforts and resources that are not necessarily available. Concentrating the effort on only well-chosen criteria may lead to a sufficiently competitive robot. Moreover, among the available initial prototypes, the robot which offers the greatest worth index is the one to work on.

Four criteria are considered to decide between configurations: the first criterion is the number of used components (the lower is the number, the less expensive is the robot), the second criterion is the robot speed capacity, the third criterion is the reliability of the robot, and the fourth criterion is the maintainability of the robot. The preference of the challenge competitors depends upon the strategy they think to be the best to compete successfully. We consider the ordinal scale $K=$ $\left\{0_{K}, a, b, c, d, 1_{K}\right\}$ to evaluate alternative against all the criteria and to express the fuzzy measure values. An example of a fuzzy measure expressing the weights given by a challenging competitor to the subsets of criteria is presented in Table 1.

TABLE 1. EXAMPLE OF COMPETITORS' PREFERENCE

\begin{tabular}{|c|c|c|c|c|c|}
\hline$I$ & $\mu(I)$ & $I$ & $\mu(I)$ & $I$ & $\mu(I)$ \\
\hline$\{1\}$ & $\mathrm{a}$ & $\{1,2,3\}$ & $1_{\mathrm{K}}$ & $\{2\}$ & $\mathrm{a}$ \\
\hline$\{1,2\}$ & $\mathrm{a}$ & $\{1,2,4\}$ & $\mathrm{d}$ & $\{2,3\}$ & $\mathrm{d}$ \\
\hline$\{1,3\}$ & $\mathrm{b}$ & $\{1,3,4\}$ & $\mathrm{c}$ & $\{2,4\}$ & $\mathrm{c}$ \\
\hline$\{1,4\}$ & $\mathrm{a}$ & $\{1,2,3,4\}$ & $1_{\mathrm{K}}$ & $\{2,3,4\}$ & $\mathrm{d}$ \\
\hline$\{3\}$ & $\mathrm{a}$ & $\{3,4\}$ & $\mathrm{a}$ & $\{4\}$ & $\mathrm{a}$ \\
\hline
\end{tabular}

According to Table 1, the challenging competitor considers that a robot having good results jointly on the second and the third criteria $I=\{2,3\}$ is preferred to an alternative having good results jointly in the second and fourth criteria $I=\{2,4\}$. The challenging competitor considers also that achieving good performances simultaneously in reliability and maintainability is not more satisfying than achieving good performance only on reliability or only on maintainability.

\section{B. Computation of the worth-index and results}

Given two different existing robots, the worth-index has been computed with initial vector of elementary performance $k^{0}$ evaluated on the scale $K$.

The initial global performance $S_{\mu}\left(k^{0}\right)$ is computed by the Sugeno integral (3) with respect to the fuzzy measure $\mu$ of Table 1.

As four criteria are considered in our study, the excellent robot, denoted $R_{\text {exce }}$, is the one having top results on the four criteria, i.e., $R_{\text {exce }}=\left(1_{K}, 1_{K}, 1_{K}, 1_{K}\right)$. In some cases, $R_{\text {exce }}$ could be only a fictive robot that could never be achieved because of limitations on the challenging competitors to provide the material, or the human resources to achieve the performances. Consequently, two cases have been considered depending on whether $R_{\text {exce }}$ is considered real or fictive. In Table 3 worth index results are given such that $R_{\text {exce }}$ is considered real and in Table 4 worth index results are given in the case where performances on the second and the third criteria cannot exceed $\mathrm{d}$ and $\mathrm{c}$ and the real excellent robot that can be achieved is $\left(1_{K}, d, c, 1_{K}\right)$. In each case, the worth index values are also reported if the robot should have to be built from scratch.
TABLE 3. WORTH INDEX COMPUTATION RESULTS

$$
R_{\text {exce }}=\left(1_{K}, 1_{K}, 1_{K}, 1_{K}\right)
$$

\begin{tabular}{|c|c|c|c|c|c|}
\hline \multicolumn{2}{|c|}{ From scratch } & \multicolumn{2}{c|}{ Robot 1} & \multicolumn{2}{c|}{ Robot 2 } \\
\hline \multicolumn{2}{|c|}{$k^{0}=\left(0_{L}, 0_{L}, 0_{L}, 0_{L}\right)$} & \multicolumn{2}{c|}{$k^{0}=(b, b, c, c)$} & \multicolumn{2}{c|}{$k^{0}=(b, d, b, a)$} \\
\hline \multicolumn{2}{|c|}{$S_{\mu}\left(k^{0}\right)=0_{L}$} & \multicolumn{2}{c|}{$S_{\mu}\left(k^{0}\right)=\mathrm{b}$} & \multicolumn{2}{c|}{$S_{\mu}\left(k^{0}\right)=\mathrm{b}$} \\
\hline$I$ & $W_{S_{\mu}}$ & $I$ & $W_{S_{\mu}}$ & $I$ & $W_{S_{\mu}}$ \\
\hline$\{1,2,3\}$ & $\mathrm{c}$ & $\{1,2,3\}$ & $\mathrm{d}$ & $\{1,2,3\}$ & $\mathrm{d}$ \\
\hline$\{1,2,4\}$ & $\mathrm{c}$ & $\{1,2,4\}$ & $\mathrm{d}$ & $\{1,2,4\}$ & $\mathrm{c}$ \\
\hline$\{1,3,4\}$ & $\mathrm{c}$ & $\{1,3,4\}$ & $\mathrm{c}$ & $\{1,3,4\}$ & $\mathrm{d}$ \\
\hline$\{1,2,3,4\}$ & $\mathrm{c}$ & $\{1,2,3,4\}$ & $\mathrm{d}$ & $\{1,23,4\}$ & $\mathrm{d}$ \\
\hline$\{2,3\}$ & $\mathrm{c}$ & $\{2,3\}$ & $\mathrm{d}$ & $\{2,3\}$ & $\mathrm{d}$ \\
\hline$\{2,4\}$ & $\mathrm{c}$ & $\{2,4\}$ & $\mathrm{c}$ & $\{2,4\}$ & $\mathrm{c}$ \\
\hline$\{2,3,4\}$ & $\mathrm{c}$ & $\{2,3,4\}$ & $\mathrm{d}$ & $\{2,3,4\}$ & $\mathrm{d}$ \\
\hline$\{1,3\}$ & $\mathrm{b}$ & $\{1,3\}$ & $\mathrm{c}$ & $\{1,3\}$ & $\mathrm{d}$ \\
\hline$\{1\}$ & $\mathrm{a}$ & $\{1\}$ & $\mathrm{c}$ & $\{1\}$ & $\mathrm{b}$ \\
\hline$\{1,2\}$ & $\mathrm{a}$ & $\{1,2\}$ & $\mathrm{c}$ & $\{1,2\}$ & $\mathrm{b}$ \\
\hline$\{1,4\}$ & $\mathrm{a}$ & $\{1,4\}$ & $\mathrm{c}$ & $\{1,4\}$ & $\mathrm{c}$ \\
\hline$\{2\}$ & $\mathrm{a}$ & $\{2\}$ & $\mathrm{c}$ & $\{2\}$ & $\mathrm{b}$ \\
\hline$\{3\}$ & $\mathrm{a}$ & $\{3\}$ & $\mathrm{b}$ & $\{3\}$ & $\mathrm{d}$ \\
\hline$\{3,4\}$ & $\mathrm{a}$ & $\{3,4\}$ & $\mathrm{b}$ & $\{3,4\}$ & $\mathrm{d}$ \\
\hline$\{4\}$ & $\mathrm{a}$ & $\{4\}$ & $\mathrm{b}$ & $\{4\}$ & $\mathrm{c}$ \\
\hline
\end{tabular}

TABLE 4. WORTH INDEX COMPUTATION RESULTS WITH PERFORMANCE LIMITATIONS

$$
R_{\text {exce }}=\left(1_{K}, d, c, 1_{K}\right)
$$

\begin{tabular}{|c|c|c|c|c|c|}
\hline \multicolumn{2}{|c|}{ From scratch } & \multicolumn{2}{c|}{ Robot 1} & \multicolumn{2}{c|}{ Robot 2} \\
\hline \multicolumn{2}{|c|}{$k^{0}=\left(0_{K}, 0_{K}, 0_{K}, 0_{K}\right)$} & \multicolumn{2}{c|}{$k^{0}=(b, b, c, c)$} & \multicolumn{2}{c|}{$k^{0}=(b, d, b, a)$} \\
\hline$W_{S_{\mu}}\left(k^{0}, N\right)=0_{L}$ & \multicolumn{2}{|c|}{$W_{S_{\mu}}\left(k^{0}, N\right)=\mathrm{b}$} & \multicolumn{2}{c|}{$W_{S_{\mu}}\left(k^{0}, N\right)=\mathrm{b}$} \\
\hline$I$ & $W_{S_{\mu}}$ & $I$ & $W_{S_{\mu}}$ & $I$ & $W_{S_{\mu}}$ \\
\hline$\{1,2,3\}$ & $\mathrm{c}$ & $\{1,2,3\}$ & $\mathrm{c}$ & $\{1,2,3\}$ & $\mathrm{c}$ \\
\hline$\{1,2,4\}$ & $\mathrm{c}$ & $\{1,2,4\}$ & $\mathrm{d}$ & $\{1,2,4\}$ & $\mathrm{c}$ \\
\hline$\{1,3,4\}$ & $\mathrm{c}$ & $\{1,3,4\}$ & $\mathrm{c}$ & $\{1,3,4\}$ & $\mathrm{c}$ \\
\hline$\{1,2,3,4\}$ & $\mathrm{c}$ & $\{1,2,3,4\}$ & $\mathrm{d}$ & $\{1,2,3,4\}$ & $\mathrm{c}$ \\
\hline$\{2,4\}$ & $\mathrm{c}$ & $\{2,4\}$ & $\mathrm{c}$ & $\{2,4\}$ & $\mathrm{c}$ \\
\hline$\{2,3,4\}$ & $\mathrm{c}$ & $\{2,3,4\}$ & $\mathrm{c}$ & $\{2,3,4\}$ & $\mathrm{c}$ \\
\hline$\{1,3\}$ & $\mathrm{b}$ & $\{1,3\}$ & $\mathrm{c}$ & $\{1,3\}$ & $\mathrm{c}$ \\
\hline$\{2,3\}$ & $\mathrm{b}$ & $\{2,3\}$ & $\mathrm{c}$ & $\{2,3\}$ & $\mathrm{c}$ \\
\hline$\{1\}$ & $\mathrm{a}$ & $\{1\}$ & $\mathrm{c}$ & $\{1\}$ & $\mathrm{b}$ \\
\hline$\{1,2\}$ & $\mathrm{a}$ & $\{1,2\}$ & $\mathrm{c}$ & $\{1,2\}$ & $\mathrm{b}$ \\
\hline$\{1,4\}$ & $\mathrm{a}$ & $\{1,4\}$ & $\mathrm{c}$ & $\{1,4\}$ & $\mathrm{c}$ \\
\hline$\{2\}$ & $\mathrm{a}$ & $\{2\}$ & $\mathrm{c}$ & $\{2\}$ & $\mathrm{b}$ \\
\hline$\{3\}$ & $\mathrm{a}$ & $\{3]$ & $\mathrm{b}$ & $\{3\}$ & $\mathrm{c}$ \\
\hline$\{3,4\}$ & $\mathrm{a}$ & $\{34\}$ & $\mathrm{b}$ & $\{3,4\}$ & $\mathrm{c}$ \\
\hline$\{4\}$ & $\mathrm{a}$ & $\{4\}$ & $\mathrm{b}$ & $\{4\}$ & $\mathrm{c}$ \\
\hline
\end{tabular}

It can be remarked that improving all the criteria leads to the higher value of worth-index, but focusing on a limited number of criteria may be sufficient to reach the same global mean expected satisfaction gain.

Analysis of Table 3 data: The most important coalition of criteria to work on from scratch are $\{2,3\}$ or $\{2,4\}$. The initial global performance values of both robots are the same, and the highest worth-index values too. Thus, it is equivalent to select Robot 1 or Robot 2 for achieving improvements. However, improving performance score of Robot 2 on criteria $\{3\}$ may be sufficient to reach the highest worth-index value while criteria $\{2,3\}$ performance values have to be improved with Robot 1 . As it may be easier to improve only one criterion Robot 2 should be chosen.

Analysis of Table 4 data: because of the impossibility to reach maximum score on criteria 2 and 3 , the coalition $\{2,3\}$ is 
less pertinent than coalition $\{2,4\}$ if the robot was built from scratch. Although the initial global performance values of both robots are the same, Robot 1 should be now preferred to Robot 2 since the worth-index reaches an higher $d$ value. The performance to improve for Robot 1 concerns criteria $\{1,2,4\}$.

In the next section, we compare our method with the one using a simple weighted arithmetic mean as an aggregation operator $H$.

\section{Computation of the worth-index with an additive operator}

In order to appreciate the contribution of our method compared to a simpler one, not taking into account the interactions between criteria and using an additive operator such as the weighted arithmetic sum $H$, let us define:

- a numerical scale $K^{\prime}=[0,1]$ in place of the ordinal scale $K$ which consequently is as an interval scale in the section C. The projection of $K$ on $K^{\prime}$ is: 'a'=[0,0.2[, ' $b$ ' $=[0.2,0.4[$, 'c'=[0.4,0.6[,'d'=[0.6,0.8[, 'e'=[0.8, 1[, $1_{\mathrm{K}}=1$.

- the weights $W=[0.12,0.35,0.30,0.23]$ of the criteria number one to four resulting from the interview of the same competitor who provided Table 1 values.

Although the possible values of the weights may not be unique, we can verify that the $W$ values are consistent with the fuzzy measure of Table 1. For instance:

- the weight of the $2^{\text {nd }}$ criterion is stronger than the weight of the $1^{\text {st }}$ criterion since

$$
\begin{gathered}
(\mu(\{2,3\})>\mu(\{1,3\})) \&(\mu(\{2,4\})>\mu(\{1,4\})) \& \\
(\mu(\{2,3,4\})>\mu(\{1,3,4\}))
\end{gathered}
$$

- the weight of the $2^{\text {nd }}$ criterion is greater or closed to the weight of the $3^{\text {rd }}$ criterion since

$$
\begin{gathered}
(\mu(\{1,3\})>\mu(\{1,2\})) \&(\mu(\{4,2\})>\mu(\{4,3\})) \& \\
(\mu(\{1,2,4\})>\mu(\{1,3,4\}))
\end{gathered}
$$

Table 5, compares the result obtained from Robot 1 and initial performance values $[b, b, c, c] \equiv[0.3,0.3,0.5,0.5]$ between our proposed method and the computation of the mean of performance improvements according to (1) when $H$ is the weighted arithmetic sum aggregation operator.

With the additive aggregation function, the expected gain $W_{H}(I)$ are strictly ordered while the initial data precision does not allow to trust such a ranking. When converted on the ordinal scale $K^{\prime}$ (according to the projection rule above, i.e. one amongst the many possible projection rules) the classes of values $W_{H}(I)$ and $W_{S_{\mu}}(I)$ differs since, for instance in Table 5, the upper d_class $\{I\}_{W_{H}(I)=d}$ contains elements of the lower c_class $\{I\}_{W_{S_{\mu}}(I)=c}$. Some elements of the b_class $\{I\}_{W_{S_{\mu}}(I)=b}$ are considered as elements of the c_class $\{I\}_{W_{H}(I)=c}$.

So such results illustrate how the computation of the worthindex with an adapted aggregation function (adapted to the level of uncertainty and precision of the context) helps to identify the criteria to improve taking into account interactions between these criteria. When the assessments collected on a system have a poor structure, e.g. ordinal information, to make arbitrary assumptions in order to use the properties of the cardinal setting may lead to unreliable results.
TABLE 5: COMPARISON ADDITIVE AND NON ADDITIVE AGREGATION FUNCTION

\begin{tabular}{|c|c|c|c|c|}
\hline \multicolumn{2}{|c|}{$k^{0}=(0.3,0.3,0.5,0.5)$} & \multicolumn{2}{c|}{$k^{0}=(b, b, c, c)$} \\
\hline \multicolumn{2}{|c|}{$H\left(k^{0}\right)=0.406$} & \multicolumn{2}{c|}{$S_{\mu}\left(k^{0}\right)=\mathrm{b}$} \\
\hline$I$ & $W_{H}$ & $I$ & $W_{S_{\mu}}$ \\
\hline$\{1,2,3,4\}$ & 0,75 & $\mathrm{~d}$ & $\{1,2,3,4\}$ & $\mathrm{d}$ \\
\hline$\{2,3,4\}$ & 0.71 & $\mathrm{~d}$ & $\{2,3,4\}$ & $\mathrm{d}$ \\
\hline$\{1,2,3\}$ & 0.67 & $\mathrm{~d}$ & $\{1,2,3\}$ & $\mathrm{d}$ \\
\hline$\{1,2,4\}$ & 0.65 & $\mathrm{~d}$ & $\{1,2,4\}$ & $\mathrm{d}$ \\
\hline$\{2,3\}$ & 0,63 & $\mathrm{~d}$ & $\{2,3\}$ & $\mathrm{d}$ \\
\hline$\{1,3,4\}$ & 0,62 & $\mathrm{~d}$ & $\{1,3,4\}$ & $\mathrm{c}$ \\
\hline$\{2,4\}$ & 0,61 & $\mathrm{~d}$ & $\{2,4\}$ & $\mathrm{c}$ \\
\hline$\{1,2\}$ & 0,57 & $\mathrm{c}$ & $\{1,2\}$ & $\mathrm{c}$ \\
\hline$\{1,3\}$ & 0,55 & $\mathrm{c}$ & $\{1,3\}$ & $\mathrm{c}$ \\
\hline$\{3,4\}$ & 0,54 & $\mathrm{c}$ & $\{3,4\}$ & $\mathrm{b}$ \\
\hline$\{2\}$ & 0,53 & $\mathrm{c}$ & $\{2\}$ & $\mathrm{c}$ \\
\hline$\{1,4\}$ & 0,52 & $\mathrm{c}$ & $\{1,4\}$ & $\mathrm{c}$ \\
\hline$\{3\}$ & 0,48 & $\mathrm{c}$ & $\{3\}$ & $\mathrm{b}$ \\
\hline$\{4\}$ & 0,46 & $\mathrm{c}$ & $\{4\}$ & $\mathrm{b}$ \\
\hline$\{1\}$ & 0,45 & $\mathrm{c}$ & $\{1\}$ & $\mathrm{c}$ \\
\hline
\end{tabular}

\section{OTHER RELATED WORKS}

The approach presented in Section 3, enters into the context of some research works whose purpose is to develop methods and tools to help systems architects to make the most satisfying decisions when designing complex technical systems particularly mechatronics ones. The search of a compromise between the 'will' to mainly satisfy the customers and the 'capacity' of the design teams to reach the fixed objectives is at the heart of this research. The types of methods and tools developed at this aim depend upon the level of uncertainty of the available data when the decision has to be made and are correlated with the stages of the design process. The earlier this stage in the design process, the more uncertain and imprecise the information.

This paper addresses the case of data with a high uncertainty level and suggests a qualitative approach [2][26]. In [27], evaluation of mechatronics concepts according to a qualitative possibilistic approach was proposed. The method takes into account the trust of the system architect in the capacity of the engineers' team to reach the design objectives. In [28] and [29] the authors investigate a quantitative possibilistic approach to respectively 'set achievable and feasible goals' and 'to identity the performance to be improved in the context of preliminary design stage'. The former formalism relies on a higher quality of information to provide since it requires from the engineers to be able to build possibility distributions of system attributes performances.

\section{CONCLUSION AND PERSPECTIVES}

In this paper is proposed a qualitative method for orienting product performance improvement at the preliminary design stage of complex products such as mechatronics products. The proposed method is based on the computation of a qualitative worth index and explicitly takes into account interaction between customers' criteria. Moreover, the method may help the decision makers to select the most promising instance of products to improve. 
An illustration example is given in the field of mechatronics and highlights the advantage of non-additive performance aggregation approaches compared to additive ones.

Further research work is engaged to build a worth index based on the qualitative possibility theory in case where a qualitative distribution can be established. QFD exploitation tools are also in progress. Our main goal is to develop decision aid tools in Mechatronics preliminary design.

\section{REFERENCES}

[1] J.M.Torry-Smith et al., "Mechatronic design - still a considerable challenge," ASME IDECT/CIE, Washington, August 28-31, 2011, 12p.

[2] P. Couturier, M. Lô, A. Imoussaten, V. Chapurlat and J. Montmain, "Tracking the consequences of design decisions in mechatronic systems engineering", Mechatronics, Volume (24), Issue 7, 2014, 763-774.

[3] Z. Babic and N. Plazibat, "Ranking of enterprises based on multicriterial analysis, International journal of production economics", vol. 56,1998, pp. 29-35.

[4] L. Berrah, G. Mauris, J. Montmain, and V. Cliville, "Efficacy and efficiency indexes for a multi-criteria industrial performance synthesized by choquet integral aggregation," International Journal of Computer Integrated Manufacturing, vol. 21, no. 4, pp. 415-425, 2008.

[5] J.-L. Marichal, "An axiomatic approach of the discrete choquet integral as a tool to aggregate interacting criteria," IEEE Transactions on Fuzzy Systems, vol. 8, no. 6, 2000, pp. 800-807.

[6] C. Labreuche and M. Grabisch, "The choquet integral for the aggregation of interval scales in multicriteria decision making," Fuzzy Sets and Systems, vol. 137, no. 1, pp. 11-26, 2003.

[7] M. Grabisch and C. Labreuche, "How to improve acts: an alternative representation of the importance of criteria in mcdm," International Journal of Uncertainty, Fuzziness and Knowledge-Based Systems, vol. 9, no. 02,2001 , pp. 145-157.

[8] C. Labreuche, "Determination of the criteria to be improved first in order to improve as much as possible the overall evaluation," in Int. Conf. on Information Processing and Management of Uncertainty in KnowledgeBased Systems (IPMU), Perugia (ITA), 2004, pp. 609-616.

[9] J. Montmain, C. Labreuche, A. Imoussaten, and F. Trousset, "Multicriteria improvement of complex systems," Information Sciences, vol.291, 2015, pp. 61-84.

[10] F. Hehenberger et al., "Hierarchical design models in the mechatronic product development process of synchronous machines", Mechatonics, Vol 20, issue 8, 2010, 864-875.

[11] ISO/IEC, IEEE Standards 15288.2008, Systems engineering - System life cycle processes (2nd edition), 2008.

[12] INCOSE, System Engineering (SE) Handbook Working Group, System Engineering Handbook, A Guide For System Life Cycle Processes And Activities, Version 3.2.1, 2011,INCOSE TP 2003002 03.2.
[13] J. Gausemeier, S. Moehringer, VDI 2206 - a new guideline for the design of mechatronic system, Mechatronic Systems, 2002.

[14] N.P. Suh, The principles of design, Oxford University Press, USA, 1990, $418 \mathrm{p}$.

[15] S. Pugh, Total Design: Integrated Methods for Successful Product Engineering. Addison-Wesley Pub. Co. New Jersey, 1991, 278p.

[16] J.R.Hauser, D. Clausing, D. The house of quality, In Harvard Business Review, May-June, 1988, 63-73.

[17] J.A. Carnevalli, P.C. Miguel, "Review, analysis and classification of the literature on QFD-Types of research, difficulties and benefits," Int. J. Production Economics, 2008, 737-754.

[18] L-K Chan, M-L Wu, "Quality function deployment: A literature review," European Journal of Operational Research, 2002, 463-497.

[19] R. Keeney, H Raiffa, Decisions with Multiple Objectives: Preferences and Value Tradeoffs, New York: Wiley, 1976.

[20] D. Krantz, D. Luce, P. Suppes, and A. Tversky,"Foundations of measurement," Vol. I: Additive and polynomial representations, 1971.

[21] M. Grabisch, I. Kojadinovic, and P. Meyer, "A review of methods for capacity identification in choquet integral based multi-attribute utility theory: Applications of the kappalab $\mathrm{r}$ package," European journal of operational research, vol. 186, no. 2, 2008, pp. 766-785.

[22] D. Bouyssou and M. Pirlot, "Conjoint measurement tools for mcdm," in Multiple Criteria Decision Analysis: State of the Art Surveys. Springer, 2005, pp. 73-112.C.

[23] C. Labreuche, "Determination of the criteria to be improved first in orde to improve as much as possible the overall evaluation," IPMU, Perugia Italy, 2004.

[24] A. Imoussaten, B. Duthil, F. Trousset, and J. Montmain, "Identifying priority lines of improvement. application to tourism data,." LFA 2016, La Rochelle, France, 2016.

[25] A. Kandel, W.J. Byatt, "Fuzzy sets, fuzzy algebra, and fuzzy statistics." Proceedings of the IEEE, 1978, vol. 66, no 12, p. 1619-1639.

[26] P. Couturier, A. Imoussaten, "A qualitative method for evaluation in conceptual design," INCOM, The premier global IFAC/IEEE Symposium on Information Control in Manufacturing, Ottawa, Canada, 2015.

[27] D. Sow, P. Couturier, A. Imoussaten, J. Montmain, "A qualitative evaluation of mechatronic concepts," REM, Compiégne, France, 2016.

[28] D. Sow, A. Imoussaten, P. Couturier, J. Montmain, "A Possibilistic Approach to Set Achievable and Feasible Goals while Designing Complex Systems," IFAC,Toulouse, France, 2017.

[29] D. Sow, A. Imoussaten, P. Couturier, J. Montmain, "A possibilistic framework for identifying the performance to be improved in the imprecise context of preliminary design," CIVESMA, Annecy, France, 2017. 